\title{
Target-site mutations (AChE-G119S and $k d r$ ) in Guangxi Anopheles sinensis populations along the China-Vietnam border
}

\author{
Chan Yang ${ }^{1,3}$, Xiangyang Feng ${ }^{2}$, Nian Liu' ${ }^{1,4}$, Mei Li ${ }^{1}$ and Xinghui Qiu ${ }^{1 *}$
}

\begin{abstract}
Background: In South Asia, the epidemiology of malaria is complex, and transmission mainly occurs in remote areas near international borders. Vector control has been implemented as a key strategy in malaria prevention for decades. A rising threat to the efficacy of vector control efforts is the development of insecticide resistance, thus it is important to monitor the type and frequency of insecticide resistant alleles in the disease vectors such as An. sinensis along the China-Vietnam border. Such information is needed to synthesize effective malaria vector control strategies.

Methods: A total of 208 adults of An. sinensis, collected from seven sites in southwest Guangxi along the ChinaVietnam border, were inspected for the resistance-conferring G119S mutation in acetylcholinesterase (AChE) by PCRRFLP (polymerase chain reaction restriction fragment length polymorphism) and $k d r$ mutations in the voltage-gated sodium channel (VGSC) by sequencing. In addition, the evolutionary origin of An. sinensis vgsc gene haplotypes was analyzed using Network 5.0.
\end{abstract}

Results: The frequencies of mutant $119 \mathrm{~S}$ of AChE were between $0.61-0.85$ in the seven An. sinensis populations. No susceptible homozygote (119GG) was detected in three of the seven sites (DXEC, LZSK and FCGDX). Very low frequencies of $k d r(0.00-0.01)$ were detected in the seven populations, with most individuals being susceptible homozygote (1014LL). The 1014F mutation was detected only in the southeast part (FCGDX) at a low frequency of 0. 03. The $1014 \mathrm{~S}$ mutation was distributed in six of the seven populations with frequencies ranging from 0.04 to 0.08 , but absent in JXXW. Diverse haplotypes of 1014L and 1014S were found in An. sinensis along the China-Vietnam border, while only one 1014F haplotype was detected in this study. Consistent with a previous report, resistant $1014 \mathrm{~S}$ haplotypes did not have a single origin.

Conclusions: The G119S mutation of AChE was present at high frequencies (0.61-0.85) in the An. sinensis populations along the China-Vietnam border, suggesting that the vector control authorities should be cautious when considering carbamates and organophosphates as chemicals for vector control. The low frequencies $(0.00-0.11)$ of $k d r$ in these populations suggest that pyrethroids remain suitable for use against $A n$. sinensis in these regions.

Keywords: Anopheles sinensis, Haplotype, Guangxi Zhuang Autonomous Region, China-Vietnam border, G119S, Knockdown resistance (kdr), Acetylcholinesterase (AChE), Voltage-gated sodium channel (VGSC)

\footnotetext{
* Correspondence: qiuxh@ioz.ac.cn

${ }^{1}$ State Key Laboratory of Integrated Management of Pest Insects and

Rodents, Institute of Zoology, Chinese Academy of Sciences, Beijing 100101,

China

Full list of author information is available at the end of the article
}

(c) The Author(s). 2019 Open Access This article is distributed under the terms of the Creative Commons Attribution 4.0 International License (http://creativecommons.org/licenses/by/4.0/), which permits unrestricted use, distribution, and reproduction in any medium, provided you give appropriate credit to the original author(s) and the source, provide a link to the Creative Commons license, and indicate if changes were made. The Creative Commons Public Domain Dedication waiver (http://creativecommons.org/publicdomain/zero/1.0/) applies to the data made available in this article, unless otherwise stated. 


\section{Background}

Malaria is a deadly vector-borne disease in tropical and subtropical regions, with 216 million malaria cases and 445,000 deaths reported in 2016 worldwide [1]. In Vietnam, 14,941 confirmed malaria cases were recorded in 2014 [2], while neighboring China is on-track to eliminate malaria by 2020 [3]. One major obstacle to elimination is the importation of malaria parasites in infected travelers which was seen in returning workers from Africa and Southeast Asia [3]. Furthermore, frequent population movement across the China-Vietnam border is a factor that poses a risk of malaria transmission and re-emergence, particularly in the adjacent Province of Guangxi. Considering that vector control remains a key strategy in malaria prevention and that its efficacy is threatened by the increasing resistance of vectors to available insecticides, there is a need to assess the actual occurrence of insecticide resistance-associated genetic mutations in Guangxi An. sinensis along the China-Vietnam border.
Carbamate (CM) and organophosphorate (OP) insecticides target insect acetylcholinesterases (AChEs). These insecticides interfere in the normal neurotransmission of insects through inhibiting the activity of AChE [4-6]. Related studies have demonstrated that G119S substitution in AChE (AChE-G119S) is associated with insect resistance to $\mathrm{OP}$ and $\mathrm{CM}$ [7-11]. Recent surveys have revealed that the G119S occurs at high frequencies in many field populations of An. sinensis in Asia [12, 13].

Insect voltage-gated sodium channels (VGSC) are the targets of a variety of insecticides including pyrethroid (PY) and organochlorine (OC) insecticides [14-16]. It has been characterized that point mutations can reduce the sensitivity of VGSCs to insecticides, thus leading to insecticide resistance [15]. Several conserved insecticide resistance-related amino acid substitutions have been documented, such as leucine (L) to phenylalanine (F) at the 1014th amino acid of VGSC [17]. L1014F is the most common mutation in VGSC in anopheline mosquitoes

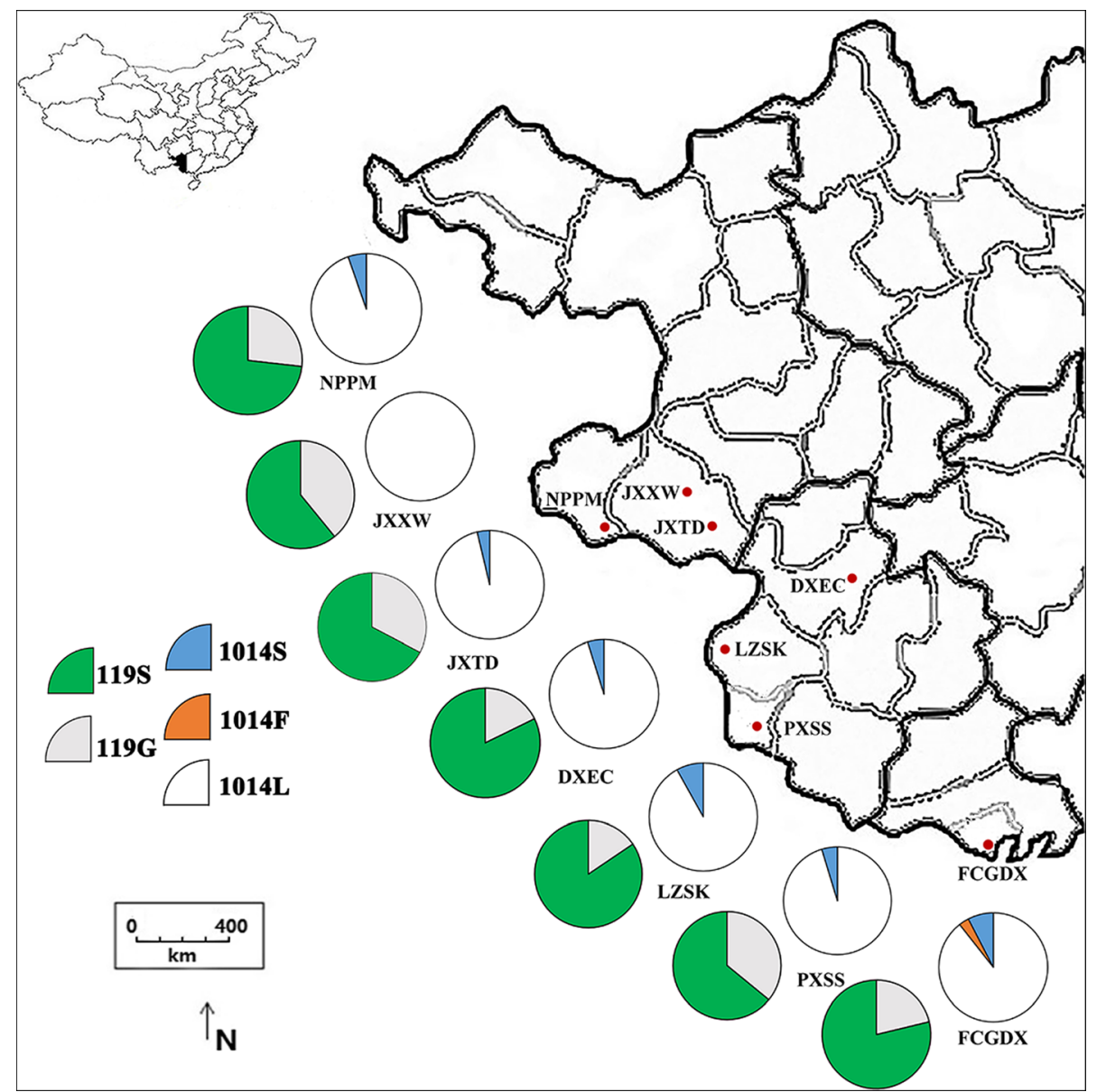

Fig. 1 Distribution and frequency of ace and kdr alleles in An. sinensis populations along the China-Vietnam border. Abbreviations: NPPM, Pingmeng, Napo County; JXXW, Xinwei, Jingxi County; JXTD, Tongde, Jingxi County; DXEC, Encheng, Daxin County; LZSK, Shuikou, Longzhou County; PXSS, Shangshi, Pingxiang County; FCGDX, Dongxing town, Fangchenggang City 


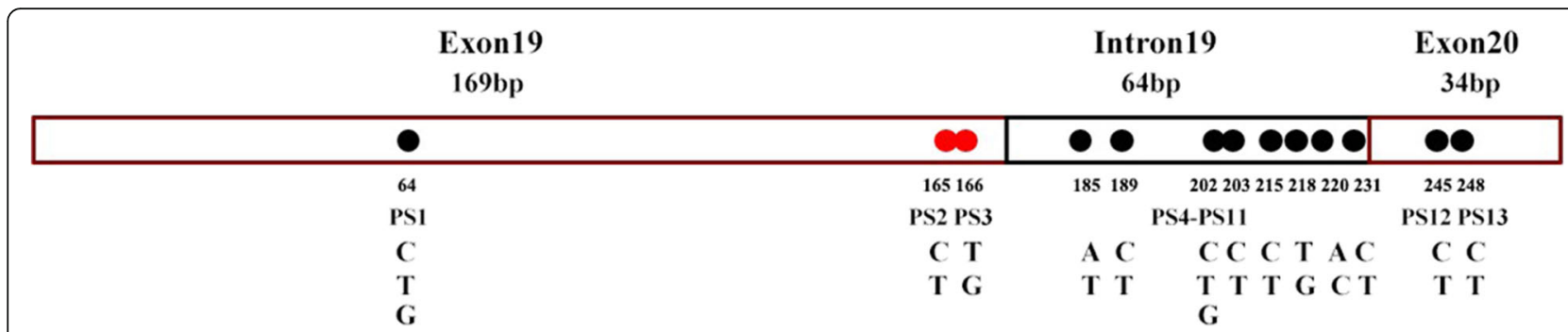

Fig. 2 The nucleotide region of An. sinensis vgsc gene addressed in this study. Dots indicate the polymorphic sites (PS) in the obtained sequences. The red dots represent sites leading to nonsynonymous mutations. The positions of PS in the 255 bp sequence are numbered below the dots. The nucleotides for each PS are given

in Africa, Asia and America. In addition to 1014F, other two mutations (1014S and 1014C) were detected in $A n$. sinensis from Asia, including China [16, 18-20]. Interestingly, $k d r$ frequencies in samples from western Guangxi of China were low, while those in samples from northeast Guangxi were high [20]. $1014 \mathrm{~S}$ was also present in An. sinensis samples from southern Vietnam [21].

In this study, insecticide resistance conferring mutations in ace-1 (encoding $\mathrm{AChE}$ ) and vgsc genes were investigated in $A n$. sinensis adult samples collected from seven sites in Guangxi along the China-Vietnam border. In addition, the possible evolutionary origin of $k d r$ haplotypes was analyzed.

\section{Methods}

The seven sample-collecting sites were located in different villages of Guangxi near the Chinese-Vietnamese border (Fig. 1). Rice is the main crop planted in these villages. The large area of rice field provides an excellent environment for mosquito breeding. The local residents usually use mosquito nets and sometimes mosquito coils (containing S-bioallethrin or prallethrin) to prevent mosquito bites. The commonly used insecticides for rice pest control in these areas are diamides (e.g. chlorantraniliprole), neonicotinoids (e.g. imidacloprid) and organophosphorates (e.g. acephate and dimethoate).
Anopheles sinensis adults used in the study were caught by light trap (wave length $365 \mathrm{~nm}$ ) between April 2015 and August 2017 at seven sites. At each sampling site, three houses were equipped with a light trap (one trap per house). The distance between houses was more than $50 \mathrm{~m}$. The light trap was placed in the bedroom (1.5-2.0 $\mathrm{m}$ above the ground). The mosquitoes trapped from 19:00 $\mathrm{h}$ to 7:00 $\mathrm{h}$ for consecutive three days from each site were pooled, morphologically identified [22], and kept in $100 \%$ ethanol at $4{ }^{\circ} \mathrm{C}$. Up to $33 \mathrm{An}$. sinensis were used for genotyping from each trapping effort.

The genomic DNA of individual mosquitoes was isolated according to the protocol described by Rinkevinch et al. [23]. Genotyping of codon 119 of An. sinensis ace-1 gene was done by PCR-RFLP [12]. The frequency of the G119S mutation in each collection was recorded. Hardy-Weinberg equilibrium (HWE) was tested using the online software GENEPOP v.4.2 [24, 25].

A fragment encompassing nucleotides corresponding to codon 1014 was amplified by PCR [20]. The PCR product from each individual was directly sequenced. Data from each sequencing was checked and cleaned manually. All confirmed DNA sequences were aligned using the Muscle programme in Mega v.6.0 [26], and polymorphic sites were identified (Fig. 2). The haplotypes of heterozygotes were clarified by T-A cloning (Transgen Biotech, Beijing, China) followed by clone

Table 1 Frequency of Ace-1 genotypes in seven An. sinensis populations along the China-Vietnam border

\begin{tabular}{|c|c|c|c|c|c|c|c|}
\hline \multirow[t]{2}{*}{ Site } & \multirow[t]{2}{*}{$n$} & \multicolumn{3}{|c|}{ Frequency } & \multicolumn{3}{|c|}{ Hardy-Weinberg equilibrium test ( $P$-value) } \\
\hline & & $\overline{\mathrm{GG}}$ & GS & SS & Probability test & Heterozygote excess & Heterozygote deficiency \\
\hline NPPM & 28 & 1 & 13 & 14 & 0.634 & 0.361 & 0.923 \\
\hline JXXW & 23 & 2 & 14 & 7 & 0.377 & 0.212 & 0.957 \\
\hline JXTD & 26 & 1 & 15 & 10 & 0.197 & 0.148 & 0.980 \\
\hline DXEC & 31 & 0 & 11 & 20 & 0.553 & 0.342 & 1.000 \\
\hline LZSK & 29 & 0 & 9 & 20 & 1.000 & 0.479 & 1.000 \\
\hline PXSS & 32 & 2 & 19 & 11 & 0.148 & 0.119 & 0.978 \\
\hline FCGDX & 33 & 0 & 14 & 19 & 0.300 & 0.175 & 1.000 \\
\hline
\end{tabular}

Abbreviations: NPPM Pingmeng, Napo County, JXXW Xinwei, Jingxi County, JXTD Tongde, Jingxi County, DXEC Encheng, Daxin County, LZSK Shuikou, Longzhou County, PXSS Shangshi, Pingxiang County, FCGDX Dongxing town, Fangchenggang City 
Table 2 Frequency of kdr genotypes in seven An. sinensis populations along the China-Vietnam border

\begin{tabular}{|c|c|c|c|c|c|c|c|}
\hline \multirow[t]{2}{*}{ Site } & \multirow[t]{2}{*}{$n$} & \multicolumn{3}{|c|}{ Frequency } & \multicolumn{3}{|c|}{ Hardy-Weinberg equilibrium test ( $P$-value) } \\
\hline & & $\mathrm{LL}$ & LF & $\mathrm{LS}$ & Probability test & Heterozygote excess & Heterozygote deficiency \\
\hline NPPM & 28 & 25 & 0 & 3 & 1.000 & 0.947 & 1.000 \\
\hline JXXW & 26 & 26 & 0 & 0 & - & - & - \\
\hline JXTD & 27 & 25 & 0 & 2 & 1.000 & 0.981 & 1.000 \\
\hline DXEC & 31 & 28 & 0 & 3 & 1.000 & 0.952 & 1.000 \\
\hline LZSK & 31 & 26 & 0 & 5 & 1.000 & 0.839 & 1.000 \\
\hline PXSS & 32 & 29 & 0 & 3 & 1.000 & 0.949 & 1.000 \\
\hline FCGDX & 33 & 26 & 2 & 5 & 1.000 & 0.708 & 1.000 \\
\hline
\end{tabular}

Abbreviations: NPPM Pingmeng, Napo County, JXXW Xinwei, Jingxi County, JXTD Tongde, Jingxi County, DXEC Encheng, Daxin County, LZSK Shuikou, Longzhou County, PXSS Shangshi, Pingxiang County, FCGDX Dongxing town, Fangchenggang City

sequencing (TSINGKE Biotech, Beijing, China). Network v.5.0 was used to analyze the evolutionary origin of $A n$. sinensis vgsc haplotypes [27].

\section{Results}

\section{The distribution and frequency of ace-1 genotypes}

The G119S allele was detected at frequencies ranging from 0.61 to 0.85 in the seven populations (Fig. 1). The three possible individual genotypes were observed, and all genotypes were detected to agree with Hardy-Weinberg equilibrium (Table 1). Notably, the susceptible homozygotes (119GG) were rare: no susceptible homozygote was detected at
DXEC, LZSK and FCGDX, and the frequencies of 119GG were less than 0.10 at the other four sites (Table 1).

Sequence polymorphisms of An. sinensis vgsc gene Thirteen nucleotide polymorphic sites (PS) were identified from the 255 bp DNA fragments individually amplified from a total of 208 mosquitoes (Fig. 2). The 1st to 3rd PSs were located on exon 19, the 4th to 11th PSs on intron 19, and the 12th and 13th PSs on exon 20. The polymorphisms in 2nd and 3rd PSs resulted in amino acid substitutions $(\mathrm{L} / \mathrm{F} / \mathrm{S})$ at codon 1014, and the nucleotide variations in 1st, 12th and 13th PSs represented synonymous mutations (Fig. 2).

Table $3 \mathrm{kdr}$ haplotypes and their frequencies in seven An. sinensis populations along the China-Vietnam border

\begin{tabular}{|c|c|c|c|c|c|c|c|c|c|}
\hline \multirow[t]{2}{*}{ Haplotype } & \multirow[t]{2}{*}{ Polymorphic sites } & \multirow{2}{*}{$\begin{array}{l}\text { GenBank } \\
\text { ID }\end{array}$} & \multicolumn{7}{|c|}{ Frequency } \\
\hline & & & NPPM & JXXW & JXTD & DXEC & LZSK & PXSS & FCGDX \\
\hline 1014L1 & CTGACGCTGCTCC & KY014584.1 & 0.214 & 0.173 & 0.333 & 0.274 & 0.194 & 0.156 & 0.273 \\
\hline 1014L2 & CTGACGCCGCCTC & KY014585.1 & 0.482 & 0.519 & 0.389 & 0.435 & 0.210 & 0.313 & 0.242 \\
\hline 1014L3 & CTGACTCCGCCTC & KY014586.1 & 0.089 & 0.192 & 0.111 & 0.081 & 0.355 & 0.250 & 0.061 \\
\hline 1014L4 & CTGACTCTGCCTC & KY014587.1 & 0.018 & & & 0.048 & 0.016 & 0.063 & 0.045 \\
\hline 1014L5 & GTGACGCCGCCTC & KY014588.1 & 0.018 & 0.019 & 0.019 & & 0.032 & 0.078 & 0.015 \\
\hline 1014L6 & CTGTCGCCGCCTC & KY014589.1 & 0.036 & 0.058 & 0.037 & 0.016 & 0.016 & 0.016 & 0.076 \\
\hline 1014L7 & CTGACGCTGCCCC & KY014590.1 & & & & 0.016 & 0.016 & 0.016 & \\
\hline 1014L8 & CTGATGCCGCCTC & KY014591.1 & 0.054 & 0.019 & 0.037 & 0.048 & 0.048 & 0.047 & 0.152 \\
\hline 1014L10 & CTGACGCTGCCTC & KP763768.1 & 0.018 & 0.019 & & 0.016 & & & \\
\hline $1014 \mathrm{~L} 15^{\mathrm{a}}$ & CTGACGCTGATCC & This study & & & 0.019 & 0.016 & 0.016 & 0.016 & 0.015 \\
\hline $1014 \mathrm{~L} 16^{\mathrm{a}}$ & CTGACTTCGCCTC & This study & & & 0.019 & & 0.016 & & \\
\hline $1014 \mathrm{~L} 17^{\mathrm{a}}$ & TTGACGCTGCCCT & This study & & & & & & & 0.015 \\
\hline $1014 \mathrm{~L} 18^{\mathrm{a}}$ & CTGACGCCTCCTC & This study & 0.018 & & & & & & \\
\hline 1014F1 & CTTACGCTGCTCC & KY014598.1 & & & & & & & 0.030 \\
\hline 101452 & CCGACGCCGCCTC & KY014594.1 & 0.036 & & 0.037 & 0.032 & 0.081 & 0.047 & 0.045 \\
\hline 101453 & CCGACTCCGCCTC & KY014595.1 & 0.018 & & & 0.016 & & & \\
\hline $1014 S 5^{\mathrm{a}}$ & CCGACGCTGCTCC & This study & & & & & & & 0.015 \\
\hline $101456^{a}$ & CCGTCGCCGCCTC & This study & & & & & & & 0.015 \\
\hline
\end{tabular}


The distribution and frequency of $k d r$ genotypes

Three $k d r$ genotypes (1014LL, 1014LF and 1014LS) were identified from the samples (Table 2). The frequencies of the susceptible homozygotes (1014LL) ranged from 0.79 (FCGDX) to 1.00 (JXXW). The resistant heterozygote 1014LS was detected at six sites at frequencies ranging from 0.07 to 0.16 , while the other resistant heterozygote 1014LF was found only at FCGDX at a frequency of 0.06 (Fig. 1). No significant deviation from HWE for the 1014 genotypes was observed in all the seven populations (Table 2).

\section{Diversity and frequency of $k d r$ haplotypes}

Eighteen $k d r$ haplotypes were identified from the $208 \mathrm{An}$. sinensis individuals (Table 3). Among them, six haplotypes (i.e. 1014L15, 1014L16, 1014L17, 1014L18, 1014S5 and 1014S6) were new records.

The geographical distribution of $k d r$ haplotypes was varied in the $A n$. sinensis populations along the China-Vietnam border (Table 3). Seven (JXXW) to 13 (FCGDG) haplotypes were detected within these populations. Of the 13 susceptible haplotypes, 1014L1, 1014L2, 1014L3, 1014L6 and 1014L8 were widely distributed at the seven sites, and 1014L1, 1014L2 and 1014L3 represented the most prevalent haplotypes. Interestingly, the newly identified susceptible haplotypes, 1014L17 and 1014L18, were uniquely distributed at FCGDX and NPPM, respectively, at a low frequency (0.02).

Four 1014S (1014S2, 1014S3, 1014S5 and 1014S6) haplotypes were identified in this study (Table 3). The haplotype 1014S2 had higher frequencies and was more widely distributed than other $1014 \mathrm{~S}$ haplotypes. The two newly identified 1014S haplotypes (1014S5 and 1014S6) and 1014F1 were only detected at FCGDX.

\section{Evolutionary origin of $1014 \mathrm{~S}$ haplotypes}

Network analysis showed that 1014S2, 1014S3 and 1014S6 were derived from 1014L2, 1014L3 and 1014L6, respectively, while both 1014S5 and 1014F1 evolved from 1014L1 through only one mutational step (Fig. 3). Notably, both 1014F1 and 1014S5 were detected only at FCGDX (Table 3).

\section{Discussion}

For all seven field populations of An. sinensis collected in Guangxi along the China-Vietnam border, the frequencies of the resistant $119 \mathrm{~S}$ allele were high. This result supports the published literature indicating that the G119S mutation is widely distributed in Guangxi [12]. The high frequency of the $119 \mathrm{~S}$ allele indicates a strong

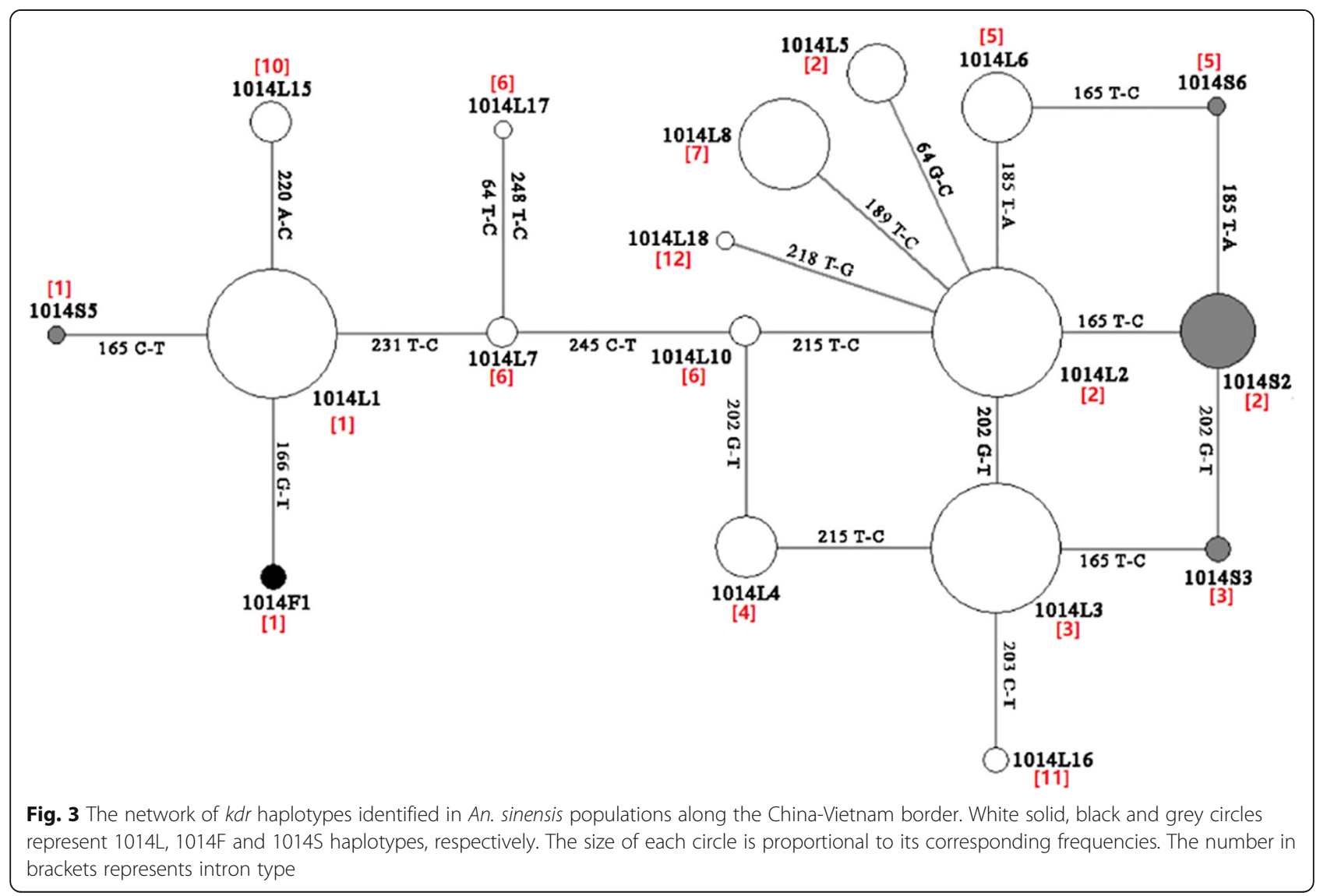


risk of resistance to $\mathrm{OP}$ and $\mathrm{CM}$ in these regions (unfortunately no $\mathrm{OP}$ or $\mathrm{CM}$ bioassay data are available to test this indication). Historically, OPs have been used for pest control in China since 1950s and, as such, the high occurrence of the G119S may be a consequence of the long-term use of $\mathrm{OP}$ in agriculture. The observations that all ace-1 genotypes did not deviate from HWE (Table 1) and that the resistant allele was present at a high frequency within the seven populations imply that mosquitoes carrying the G119S mutation may suffer no fitness cost under current natural conditions, or the cost mediated by G119S substitution may possibly be offset by unknown fitness modifiers.

Two different $k d r$ mutations (1014S and 1014F) were identified in this study (Table 2, Fig. 1). These insecticide resistance-associated mutations occurred in heterozygous forms and at very low frequencies in these areas. Interestingly, the $1014 \mathrm{C}$ mutation, which is widespread and present at relatively high frequencies in northeast Guangxi [20], was not detected in this survey. In addition, 1014F1, which is widely distributed in several provinces of China including Guangxi [20], was detected only at FCGDX. By contrast, the 1014S allele was widely distributed along the border. The distinct distribution of the $1014 \mathrm{~S}$ allele is likely a consequence of independent mutational events in different geographical locations. The distribution pattern observed in this study is consistent with previous observations showing that the frequency of $k d r$ mutations decreases towards south and west from northeast [18-20, 28-30].

The present study demonstrates the geographical heterogeneities of $k d r$ haplotypes and the presence of location-specific haplotypes (Table 3). For example, the haplotypes 1014S5 and 1014S6 were only detected in FCGDX. Furthermore, the genealogical analysis of vgsc haplotypes suggests that the 1014S2, 1014S3 and 1014S6 may have evolved from 1014L2, 1014L3 and 1014L6, respectively, adding support to the hypothesis that $k d r$ mutations do not have a single origin [20]. Multiple origins of $k d r$ mutations have also been documented in several other insect species [31, 32].

In the remote villages studied, no regular vector control programme has been implemented. The lack of pyrethroid selection pressure on the mosquito populations may explain why all $v g s c$ alleles exhibit HWE, and why $k d r$ is rare (Table 2). A recent preliminary survey indicated no loss of susceptibility to deltamethrin in $A n$. sinensis adults collected from sampling sites same as in this study (conducted in June to August 2018 using the contact bioassay protocol recommended by China CDC, Dr. Fengxia Meng; personal communications). Based on the findings in this study, we suggest that pyrethroids remain suitable for use against $A n$. sinensis. Noting that a strong insecticide resistance management programme should be implemented to maintain the susceptibility of $v g s c$ alleles, it is recommended that the application of pyrethroids should not be taken as the sole measure for vector control and should be used in rotation or alongside insecticides with alternative modes of action.

\section{Conclusions}

High frequencies (0.61-0.85) of the G119S mutation in $\mathrm{AChE}$ and low frequencies of $k d r$ mutations $(0.00-0.11)$ were detected in An. sinensis populations along the China-Vietnam border. 1014S was the most common $k d r$ mutation in these areas. Network analysis revealed that the $1014 \mathrm{~S}$ mutation did not have a single origin. The data suggest that the vector control authorities should be cautious when considering carbamates and organophosphates as control agents. Instead, pyrethroids are suitable for An. sinensis control in these regions.

\section{Abbreviations \\ AChE: Acetylcholinesterase; CM: Carbamate insecticides; Guangxi: Guangxi Zhuang Autonomous Region, China; HWE: Hardy-Weinberg equilibrium; kdr: Knockdown resistance; OC: Organochlorine insecticides; \\ OP: Organophosphorus insecticides; PCR: Polymerase chain reaction; PY: Pyrethroid insecticides; RFLP: Restriction fragment length polymorphism; VGSC: Voltage-gated sodium channel}

\section{Acknowledgements \\ The authors would thank Ms Hui Yan (Guangxi CDC) for help in collecting samples. We thank the anonymous reviewers for their excellent comments. \\ Funding \\ This work was supported by the grant 2017ZX10303404002004. The funders had no role in the study design, data collection, analysis, decision to publish or preparation of the manuscript.}

\section{Availability of data and materials}

All datasets are presented in this published article. Representative sequences were submitted to the GenBank database under the accession numbers $\mathrm{MH} 384262-\mathrm{MH} 384267$

\section{Authors' contributions}

$\mathrm{XHQ}$ and $\mathrm{XYF}$ conceived the study. $\mathrm{CY}$ and NL performed the experiment. $\mathrm{CY}, \mathrm{NL}$ and $\mathrm{XHQ}$ analyzed the data. $\mathrm{XHQ}, \mathrm{CY}$ and $\mathrm{XYF}$ wrote the paper. XYF and $\mathrm{ML}$ contributed to sample collection. All authors read and approved the final manuscript.

Ethics approval and consent to participate Not applicable.

\section{Consent for publication}

Not applicable.

\section{Competing interests}

The authors declare that they have no competing interests.

\section{Publisher's Note}

Springer Nature remains neutral with regard to jurisdictional claims in published maps and institutional affiliations.

\section{Author details}

${ }^{1}$ State Key Laboratory of Integrated Management of Pest Insects and Rodents, Institute of Zoology, Chinese Academy of Sciences, Beijing 100101, China. ${ }^{2}$ Guangxi Zhuang Autonomous Region Centre for Diseases Control and Prevention, Nanning 530028, China. ${ }^{3}$ University of Chinese Academy of 
Sciences, Beijing 100049, China. ${ }^{4}$ Institute of Physical Science and Information Technology, Anhui University, Hefei, China.

Received: 21 September 2018 Accepted: 7 January 2019

Published online: 07 February 2019

\section{References}

1. WHO. World Malaria Report 2017. Geneva: World Health Organization; 2017.

2. Goldlust SM, Thuan PD, Giang DDH, Thang ND, Thwaites GE, Farrar J, et al. The decline of malaria in Vietnam, 1991-2014. Malar J. 2018;17:226.

3. Li JH, Li J, Qin YX, Guo CK, Huang YM, Lin Z, et al. Appraisal of the effect and measures on control malaria for 60 years in Guangxi. J Trop Med. 2014; 14:361-4.

4. Bajgar J. Organophosphates/nerve agent poisoning: mechanism of action, diagnosis, prophylaxis, and treatment. Adv Clin Chem. 2004;38:151-216.

5. Fukuto TR. Mechanism of action of organophosphorous and carbamate insecticides. Environ Health Perspect. 1990;87:245-54.

6. Wang Y, Chen C, Zhao X, Wang Q, Qian Y. Assessing joint toxicity of fou organophosphate and carbamate insecticides in common carp (Cyprinus carpio) using acetylcholinesterase activity as an endpoint. Pestic Biochem Physiol. 2015;122:81-5.

7. Chen Z, Newcomb R, Forbes E, McKenzie J, Batterham P. The acetylcholinesterase gene and organophosphorus resistance in the Australian sheep blowfly, Lucilia cuprina. Insect Biochem Mol Biol. 1998;31: 805-16

8. Dong SL, Andrews MC, Li F, Moores GD, Han ZJ, Williamson MS. Acetylcholinesterase genes and insecticide resistance in aphids. Chem Biol Interact. 2005:157:373-4

9. Khajehali J, Van Leeuwen T, Grispou M, Morou E, Alout H, Weill M, et al. Acetylcholinesterase point mutations in European strains of Tetranychus urticae (Acari: Tetranychidae) resistant to organophosphates. Pest Manag Sci. 2010;66:220-8

10. Li CX, Dong YD, Song FL, Zhang XL, Zhao TY. An amino acid substitution on the acetylcholinesterase in the field strains of house mosquito, Culex pipiens pallens (Diptera: Culicidae) in China. Entomol News. 2009;120:464-75.

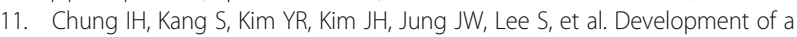
low-density DNA microarray for diagnosis of target-site mutations of pyrethroid and organophosphate resistance mutations in the whitefly Bemisia tabaci. Pest Manag Sci. 2011;67:1541-8.

12. Feng $X$, Yang $C$, Yang $Y$, Li J, Lin K, Li M, et al. Distribution and frequency of G119S mutation in ace-1 gene within Anopheles sinensis populations from Guangxi, China. Malar J. 2015;14:470-4.

13. Baek JH, Kim HW, Lee WJ, Lee SH. Frequency detection of organophosphate resistance allele in Anopheles sinensis (Diptera: Culicidae) populations by real-time PCR amplification of specific allele (rtPASA). J Asia Pac Entomol. 2006:9:375-80

14. Dong K. Insect sodium channels and insecticide resistance. Invertebr Neurosci. 2007;7:17-30

15. Dong K, Du YZ, Rinkevich F, Nomura Y, Xu P, Wang LX, et al. Molecular biology of insect sodium channels and pyrethroid resistance. Insect Biochem Mol Biol. 2014;50:1-17.

16. Silva APB, Santos JMM, Martins AJ. Mutations in the voltage-gated sodium channel gene of anophelines and their association with resistance to pyrethroids - a review. Parasit Vectors. 2014;7:450.

17. Rinkevich FD, Du YZ, Dong K. Diversity and convergence of sodium channel mutations involved in resistance to pyrethroids. Pestic Biochem Physiol. 2013;106:93-100

18. Chang X, Zhong D, Lo E, Fang Q, Bonizzoni M, Wang X, et al. Landscape genetic structure and evolutionary genetics of insecticide resistance gene mutations in Anopheles sinensis. Parasit Vectors. 2016:9:228.

19. Wang Y, Yu W, Shi H, Yang Z, Xu J, Ma Y. Historical survey of the $k d r$ mutations in the populations of Anopheles sinensis in China in 1996-2014. Malar J. 2015;14:120-9.

20. Yang C, Feng X, Huang Z, Li M, Qiu X. Diversity and frequency of $k d r$ mutations within Anopheles sinensis populations from Guangxi, China. Malar J. 2016;15:411-8.

21. Verhaeghen K, Van Bortel W, Ho DT, Sochantha T, Keokenchanh K, Coosemans M. Knockdown resistance in Anopheles vagus, An. sinensis, An. paraliae and An. peditaeniatus populations of the Mekong region. Parasit Vectors. 2010;3:59
22. Lu B, Wu H. Classification and identification of important medical insects of China. 1st ed. Zheng Zhou: Henan Science and Technology Publishing House; 2003.

23. Rinkevich FD, Zhang L, Hamm RL, Brady SG, Lazzaro BP, Scott JG. Frequencies of the pyrethroid resistance alleles of VSSC1 and CYP6D1 in house flies from the eastern United States. Insect Mol Biol. 2006;15:157-67.

24. Raymond M, Rousset F. GENEPOP (version 1.2): Population genetics software for exact tests and ecumenicism. J Hered. 1995;86:248-9.

25. Rousset F. GENEPOP '007: a complete re-implementation of the GENEPOP software for Windows and Linux. Mol Ecol Resour. 2008;8:103-6.

26. Tamura K, Stecher G, Peterson D, Filipski A, Kumar S. MEGA6: Molecular Evolutionary Genetics Analysis version 6.0. Mol Biol Evol. 2013;30:2725-9.

27. Bandelt $\mathrm{HJ}$, Forster $\mathrm{P}$, Rohl A. Median-joining networks for inferring intraspecific phylogenies. Mol Biol Evol. 1999;16:37-48.

28. Zhong D, Chang X, Zhou G, He Z, Fu F, Yan Z, et al. Relationship between knockdown resistance, metabolic detoxification and organismal resistance to pyrethroids in Anopheles sinensis. PLoS One. 2013;8:e55475.

29. Qin Q, Li YJ, Zhong DB, Zhou N, Chang XL, Li C, et al. Insecticide resistance of Anopheles sinensis and An. vagus in Hainan Island, a malaria-endemic area of China. Parasit Vectors. 2014;7:92.

30. Chang XL, Zhong DB, Fang Q, Hartsel J, Zhou GF, Shi LN, et al. Multiple resistances and complex mechanisms of Anopheles sinensis mosquito: a major obstacle to mosquito-borne diseases control and elimination in China. PLoS Neglect Trop Dis. 2014;8:e2889.

31. Anstead JA, Williamson MS, Denholm I. Evidence for multiple origins of identical insecticide resistance mutations in the aphid Myzus persicae. Insect Biochem Mol Biol. 2005;35:249-56.

32. Rinkevich FD, Hedtke SM, Leichter CA, Harris SA, Su C, Brady SG, et al. Multiple origins of $k d r$-type resistance in the house fly, Musca domestica. PLoS One. 2012;7:e52761.

Ready to submit your research? Choose BMC and benefit from:

- fast, convenient online submission

- thorough peer review by experienced researchers in your field

- rapid publication on acceptance

- support for research data, including large and complex data types

- gold Open Access which fosters wider collaboration and increased citations

- maximum visibility for your research: over $100 \mathrm{M}$ website views per year

At $\mathrm{BMC}$, research is always in progress.

Learn more biomedcentral.com/submissions 